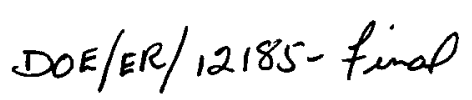

\title{
INJECTION MOLDING OF PLASTICS FROM AGRICULTURAL MATERIALS
}

\section{Principal Investigator: Mrinal Bhattacharya \\ Department of Biosystem and Agricultural Engineering

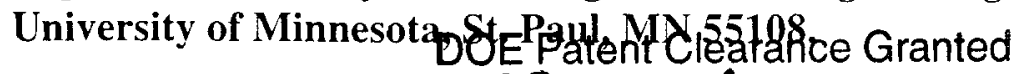 \\ DOE CONTRACT \#: DE-FG02-96ER12185 \\ OBJECTIVE}

The objective of this research was to conduct a systematic study to relate injection molding parameters to properties of blends of starch and synthetic polymer. Blends of normal (25 $\%$ amylose) and high amylose (50 and 70\% amylose) corn starch (containing between 60 and 70 $\%$ of the mixture by weight) and synthetic polymer were used in this research. Two different classes of synthetic polymer were be used. The first is a fully biodegradable synthetic polyester while the second is a non-degradable polyolefin. The blends were made in an extruder. Specifically, the objective included: i) determine the rheological properties of the blends, ii) study the effect of injection molding parameters on weld line strength, iii) evaluate the effect of molding parameters on the tensile, flexural and impact strength, residual stresses, crystallinity, density variation, morphology, and shrinkage of starch/synthetic polymer blends, and iv) test the degradability of the blends. From this study we wished to develop a thorough understanding of the injection molding process and gain significant insight into designing molds and aiding in developing products cheaply and efficiently.

\section{RESULTS:}

Corn starch was melt-blended in a twin-screw extruder with ethylene vinyl acetate (EVAMA) and polyethylene (EMA), each having a maleic anhydride functional group that could interact with the hydroxyl groups in the starch. The percentage of starch in the blend can be as high as $70 \%$ by weight. These blends were injection molded at different melt temperatures, screw speeds, injection pressures, and back pressures. The effect of these processing parameters on the tensile strength, percentage elongation, break energy, flexural modulus, and flexural modulus are reported. Results from statistical analysis indicate that temperature and weldline affected some of the properties. Samples with weldline had lower tensile strength, break energy, and percent elongation for starch/EVAMA blends. Similarly, samples with weldline had lower tensile strength and flexural modulus for starch/EMA blends. Starch/EVAMA blends absorbed between $22 \%$ and $37 \%$ by weight of water over a three-month period, while starch/EMA blends absorbed between $20 \%$ and $27 \%$ over the same period. The diffusion mechanism varied from Fickian to anomalous, depending on the process conditions. For both blends, the process parameters had similar effects on the equilibrium water up-take and relaxation time. The effect of the composition, starch type (wheat or corn), inclusion of fibers, and the presence or absence of weldline on the mechanical properties of injection molded starch and synthetic polymer blends were studied as a function of time and summarized. In addition, the effect on the mechanical properties after mixing a fraction of reground starch/EVAMA and starch/EMA materials generated from runners and sprues with the respective virgin blended material were studied. Corn starch yielded better tensile properties than wheat starch or wheat flour. Weldline 


\section{DISCLAIMER}

This report was prepared as an account of work sponsored by an agency of the United States Government. Neither the United States Government nor any agency thereof, nor any of their employees, makes any warranty, express or implied, or assumes any legal liability or responsibility for the accuracy, completeness, or usefulness of any information, apparatus, product, or process disclosed, or represents that its use would not infringe privately owned rights. Reference herein to any specific commercial product, process, or service by trade name, trademark, manufacturer, or otherwise does not necessarily constitute or imply its endorsement, recommendation, or favoring by the United States Government or any agency thereof. The views and opinions of authors expressed herein do not necessarily state or reflect those of the United States Government or any agency thereof. 


\section{DISCLAIMER}

Portions of this document may be illegible in electronic image products. Images are produced from the best available original document. 
(knitline) strength ranged from $55-95 \%$ of nonweldline values and was dependent on composition. Up to $25 \%$ of reground materials can be used without any detrimental effect on properties. Addition of fibers increased the tensile but not the flexural strength, though the weldline properties of samples containing fiber were poor. Fibers with medium aspect ratios (33.5) were found to give better properties. Soaking in water reduced the tensile properties significantly. The tensile properties for most compositions were invariant with time.

Corn starch with different contents of amylopectin to amylose ratio were melt-blended in a corotating twin-screw extruder with the synthetic polymers, ethylene-vinyl acetate, low density polyethylene and high density polyethylene having anhydride functionality. Four different starches were used: unmodified waxy maize, containing $100 \%$ amylopectin; industrial corn, containing approximately $70 \%$ amylopectin and $30 \%$ amylose; common corn, possessing approximately 50\% amylopectin and 50\% amylose; and a unmodified high amylose starch, consisting of approximately $30 \%$ amylopectin and $70 \%$ amylose. The concentration of starch in the blends was kept constant at $70 \%$ by weight. The influence of starch type on processing parameters (pressure, torque, and energy), tensile strength, percent elongation, flexural strength, and water absorption was investigated. Torque and energy data showed that the blends with starch containing high amylopectin content had the maximum value while the blend containing the highest amylose content required the lowest torque. Degradation or debranching of the branched macromolecular components of the starch during the thermomechanical processing treatment was observed from a gel-permeation chromatograph. Tensile strength and water absorption were correlated with the torque generated during blending. The effect of amylose to amylopectin in starch on tensile properties, flexural properties, and storage time are discussed. The tensile and flexural strength increased at the amylose content of $70 \%$ and is higher in waxy maize starch (highly branched) blends, presumably due to more crosslinking. Samples with weldline had a lower tensile strength, flexural modulus, and percent elongation. Influence of starch type on water absorption is also discussed. Blends containing waxy maize starch absorb more water than those containing a higher amylose content of $70 \%$. In most of the samples, the equilibrium water uptake was between 20 to $24 \%$ over a period of 80 days. Differential scanning calorimeter (DSC), dynamic mechanical analyzer (DMA), scanning (SEM) and transmission electron microscope (TEM), and optical microscopy (OM) were used to evaluate the phase morphology. DSC studies indicated that starch granules underwent melting with each subsequent processing step. This was also confirmed from the optical photomicrographs which indicated the starch granule size decreased after each subsequent processing step. DMA studies showed that the blends exhibited two distinct glass transitions, one for each component, and that the glass transition temperature of starch decreased as the amylose content increased in the starch blends. Microscopy studies indicated that the starch phase became finer as the amylopectin content in the starch increased. For blends containing waxy starch, a co-continuous phase with synthetic polymers was evident.

In order to develop blends containing biodegradable polyester with natural polymers containing a significant amount of the latter, it was decided to modify the polyester by attaching a functional group on the backbone. Polycaprolactone-graft-maleic anhydride (PCL-g-MA) copolymer was prepared by grafting maleic anhydride onto PCL in a batch mixer and in an extruder using dicumyl peroxide as the initiator. The graft content was determined with the volumetric method by converting the anhydride functions to acid groups and then titrating with 
ethanolic potassium hydroxide. The grafted polymer was extracted with xylene to remove any unreacted monomer before the estimation step. The effects of temperature and the various concentrations of the initiator and monomer used for the grafting reaction were investigated. The presence of residual initiator in the reaction product was checked using thin-layer chromatography. Molecular weight determination was carried out for the pure and grafted polymer using gel permeation chromatography to determine if chain scission was present. Results indicated that maleic anhydride is grafted onto PCL using free radical initiators. The grafting reaction was confirmed by FTIR and NMR techniques. FTIR spectra showed absorption bands around 1785 and $1858 \mathrm{~cm}^{-1}$. NMR spectra gave signals for methine proton at $3.47 \mathrm{ppm}$. For a given peroxide level, a higher temperature or residence (reaction) time gave a higher percentage of grafted MA. There was an optimum temperature and initiator concentration after which the percentage of MA grafted on PCL decreased. The number average molecular weight, tensile strength, and the percent elongation of PCL-g-MA were comparable to those of PCL before grafting. We extended the grafting of functional groups on polymers to several other biodegradable polyesters. Using this technique, maleic anhydride (MAn) was grafted onto other aliphatic and aromatic/aliphatic copolyesters by reactive extrusion in the presence of a free radical initiator using a twin screw extruder. Another form of compatibilizers developed included starch-g-poly( $\varepsilon$-caprolactone). Polycaprolactone (PCL) was grafted onto starch through introduction of urethane linkage. The grafting reaction was carried out in two steps. The first step was the reaction of hydroxyl terminated PCL with toluene 2,4-diisocyanate. The isocyanate terminated PCL was then reacted with starch to obtain starch-g-PCL. Copolyesters of PCL and maleic anhydride were synthesized using Stannous octoate $\left(\mathrm{Sn}(\mathrm{oct})_{2}\right)$ as a catalyst and 2,2'azobisisobutyronitrile (AIBN) as an initiator [8]. NMR studies indicated that the succinic anhydride units were incorporated individually either to the polymer chain end or backbone. Anhydride content in the polymer and gel permeation chromatograph (g.p.c.) studies indicated that the maleic anhydride acts as the true initiating species rather than as a comonomer in the system.

The properties of blends of starch and aliphatic biodegradable polyesters were evaluated. The aliphatic polyesters used include: poly $\varepsilon$-caprolactone, polybutylene succinate, and a butanediol-adipate-terephthalate copolymer. To improve the compatibility between the starch and the synthetic polyester, a compatibilizer containing an anhydride functional group incorporated on to the polyester backbone was used. The addition of a small amount of compatibilizer increased the strength significantly over the uncompatibilized blend. For the compatibilized blend, the tensile strength was invariant with starch content when compared to the original polyester, while it decreased with increase in starch content for the uncompatibilized blend. Blends displayed a sharp intake of water, and those containing butanediol-adipateterephthalate copolymer had a higher water absorption than those containing the other polyester. Each blend displayed two glass transitions, one corresponding to the polyester and the other corresponding to starch. For compatibilized blends, the glass transition temperature of starch in the blend is lower than that observed for the uncompatibilized blend. For all polyester blends, those containing $99 \%$ amylopectin starch at $70 \%$ level had the lowest crystallinity which otherwise decreased with decreased amylopectin level in the starch. Blend morphology indicates that the starch phase become finer as the amylopectin in the blend increased. Also, a higher 
starch content led to greater melting of the starch granules, and at $70 \%$ starch by weight, a cocontinuous phase between the starch and the synthetic polymer exists.

Rheological properties of individual polyesters and their blends have been evaluated. These blends displayed shear and extension thinning. The shear viscosity ( $\eta$ ) obtained by extrusion feeding the material through the slit die was lower than that obtained from the capillary rheometer indicating the effect of processing history on the rheology of these materials. Lower starch content and higher temperature gave lower $\eta$ but higher first normal stress difference $\left(\mathbf{N}_{\mathbf{1}}\right)$. The stress growth behavior of the blends showed strain and temperature dependence. Blends with higher starch content had nonlinear viscoelasticity compared to low starch content blends at the same shear rates. Blends with higher starch content relaxed faster both in stress relaxation tests and in the step-strain experiments. Increasing the temperature increased the relaxation behavior of blends with lower starch content but no appreciable effect on blends with higher starch content was observed. Both blends seem to have time-strain separability at long durations in the step-strain experiments. Blends with $70 \%$ starch did not show significant variation with temperature in the elongational, low shear viscosities, and relaxation modulus.

The rheological properties of three partially crystalline aliphatic polyesters poly- $\varepsilon$ caprolactone (PCL), polylactic acid (PLA), and polyhydroxybutyrate-co-hydroxyvalerate (PHBV), which are biodegradable, were investigated under steady shear conditions. Shear viscosity $(\eta)$, first normal stress difference $\left(\mathbf{N}_{\mathbf{1}}\right)$, and dynamic properties ( $\mathbf{G}$ ' and $\mathbf{G}$ ') , were measured for each polymer. For all materials, data using rotational instruments could be obtained in the shear rate range $0.1<\dot{\gamma}<10.0 \mathrm{~s}^{-1}$. High shear viscosity data was obtained using a capillary rheometer. Gel permeation chromatography indicates that after the completion of a time-sweep experiment both PLA and PHBV undergo degradation. Thermal degradation rate constants for PLA and PHBV were determined from the time-sweep data. Effects of temperature on the material functions were determined. Results are discussed in terms of variations in the molecular characteristics on rheological properties and their possible influence on processability of these materials. Data indicates that material functions are proportional to the molecular weight for PCL and PLA samples, and directly related to the HV content in the PHBV samples.

Transient shear and extensional properties of two grades of partially crystalline biodegradable aliphatic polyesters, poly- $\varepsilon$-aprolactone (PCL), were determined. The magnitudes of the stress-overshoot during stress growth experiments were smaller than those typically observed for other polymers. Higher melt temperature and higher strain led to faster relaxation, while the lower molecular weight PCL 767 relaxed faster than the higher molecular weight PCL 787. The relaxation moduli are independent of strain for strain values below 0.1 . Transient extensional measurements were conducted at strain rates of 0.01 to $1.0 \mathrm{~s}^{-1}$. At small stresses the extensional viscosity has the threefold value of shear viscosity as predicted by Trouton. There appeared to be no steady state regime for either grades of PCL studied and as a result $\eta_{\mathrm{e}}(\varepsilon)$ could not be determined. The departure from the linear limit is the fastest for the highest extensional rate. Extension thickening behavior is observed at Hencky strains ranging from 1. 0 to 2.0. PCL 767 displayed greater extension thickening than PCL 787 at the same temperatures. 
The Wagner integral constitutive equation was found to give an acceptable fit to the stress growth data in shear and extension, with the fit being better for PCL 767 than for PCL 787.

Crystallization behavior of the blends of starch and maleated polyolefins was studied at $50^{\circ} \mathrm{C}$ over a period of 20 weeks using wide angle X-ray diffraction (WAXS). The variation of mechanical properties (tensile and flexural) and stress relaxation behavior of the blends stored at $50^{\circ} \mathrm{C}$ and $-10^{\circ} \mathrm{C}$ were studied over the same period. The starch content in the blends was $70 \%$ by weight. An increase in the tensile properties of all the blends was observed in the first five weeks for samples kept at both temperature conditions. Blend samples kept at $50^{\circ} \mathrm{C}$ had higher tensile strengths than the samples at $-10^{\circ} \mathrm{C}$. Flexural strength remained constant over the duration of time. Freshly molded specimens relaxed faster than the samples aged at either temperatures. Xray diffraction patterns showed that the starch was completely melted and had lost its crystallinity. Also, starch blends with EVA did not show any crystalline structure. The crystallinity in the starch blends with polyethylene was mainly due to the crystallinity of the synthetic polymer. The X-ray patterns of pure synthetic polymers were not found to be different from their functionalized counterparts. Crystal intensity was found to decrease for all the polyethylene blends. The effect of crystallinity on the mechanical properties is discussed.

Stress relaxation behaviour of injection moulded starch/polyolefin blends was studied. In one study, the starch content was kept constant at $70 \%$ while the amylose to amylopectin ratio was varied. In the second study, the starch content in the blend was varied. A small amount of maleic anhydride functionalized synthetic polymer ( $5 \%$ by weight) was added to reactively compatibilize the starch and the synthetic polymer. Starch/HDPE and starch/LDPE blends had a ductile behavior while starch/EVA blends displayed rubbery characteristics. Blends containing EVA relaxed the fastest while those containing LDPE took the longest time to relax. A double logarithmic plot of stress versus time at constant strain was linear and the slopes of the plots were insensitive to starch type but were affected by the starch content. Internal stress developed during moulding was also estimated from the stress-relaxation measurement. The stressrelaxation data fitted several empirical stress-time non-linear models well.

\section{SIGNIFICANCE OF FINDINGS :}

We have developed polymer blends having significant agricultural components $(70 \%$ by weight). This is a significant improvement over products currently available in the market which contain between $30-50 \%$ starch by weight. A commercially sold chew-toy for pets that is a direct result of the project. A cutlery (tableware) formulation also resulted from this project and is undergoing FDA inspection. It is possible that for certain applications, fully biodegradable materials that costing $\$ 1.00 / \mathrm{lb}$ can be developed.

\section{PUBLICATIONS RESULTING FROM THIS PROJECT.}

1. John, J., Tang, J., Yang, Z., and Bhattacharya, M. 1997. Synthesis and characterization of anhydride functional polycaprolactone. J. Polymer Sci. Part A: Polym. Chem. 35:1139-1148.

2. Jacob, J., Tang, J., and Bhattacharya, M. 1998. Grafting of oxazoline functional group on polycaprolactone. J. Appl. Polym. Sci. 67:1947-1955. 
3. Mani, R., and Bhattacharya, M. 1998. Properties of injection molded starch/synthetic polymer blends III. Effect of amylose to amylopectin ratio in starch. European Polymer J. 34:14671475.

4. Mani, R., and Bhattacharya, M. 1998. Properties of injection molded starch/synthetic polymer blends IV. Thermal and morphological studies. European Polymer J. 34:1477-1487.

5. Mani, R., Bhattacharya, M., and Tang, J. 1999. Functionalization of polyester with maleic anhydride by reactive extrusion. J. Polymer Sci. Part A: Polym. Chem. 37:1693-1702.

6. Mani, R., Tang, J., and Bhattacharya, M. 1998. Synthesis and characterization of starch-gpolycaprolcatone as compatibilizer for starch polycaprolactone blend. Macromolecular Rapid Communications 19:283-286.

7. Mani, R., Currier, J. and Bhattacharya, M. 2000. Copolymerization of $\varepsilon$-caprolactone with maleic anhydride: synthesis and characterization. J. Appl. Poly. Sci. (in-press).

8. Mani, R. and Bhattacharya, M. Properties of injection moulded blends of starch and modified biodegradable polyesters. European Polymer J. (accepted).

9. Ramkumar, D. H. S., Bhattacharya, M., and Zhang, D. 1997 High shear and transient viscosity of starch and maleated ethylene vinyl acetate copolymer. Polymer Networks and Blends 7: 51-59.

10. Ramkumar, D. H.S., and Bhattacharya, M. 1998. Steady shear and dynamic properties of biodegradable polyesters. Poly. Engg. Sci. 38:1426-1435.

11. Kapoor, B, and Bhattacharya, M. 1999. Transient shear and extensional properties of biodegradable polycaprolactone. Poly. Engg. Sci. 39:676-687.

12. Ramkumar, D. H. S., and Bhattacharya, M. 1997. Effects of crystallinity on the mechanical properties of starch/synthetic polymer blends. J. Materials Sci. 32:2565-2572.

13. Bhattacharya, M. 1998. Stress relaxation of starch/synthetic polymer blends. J. Materials Sci. 33: 4131-4139. 